\title{
Combinatorial synthesis of magnesium tin nitride semiconductors
}

Ann L. Greenaway,1* Amanda L. Loutris,1 Karen N. Heinselman,1 Celeste L. Melamed,2,1 Rekha R. Schnepf,2,1 M. Brooks Tellekamp,1 Rachel Woods-Robinson,1,3,4 Rachel Sherbondy,5,1 Dylan Bardgett,1 Sage Bauers,1 Andriy Zakutayev,1 Steven T. Christensen,1 Stephan Lany,1 Adele C. Tamboli 1,2

1 Materials and Chemistry Science and Technology Directorate, National Renewable Energy Laboratory, Golden, Colorado 80401, USA

2 Department of Physics, Colorado School of Mines, Golden, Colorado 80401, USA

3 Applied Science and Technology Graduate Group, University of California, Berkeley, CA 94720, USA

4 Energy Technologies Area, Lawrence Berkeley National Laboratory, Berkeley, CA 94702, USA

5 Department of Metallurgical and Materials Engineering, Colorado School of Mines, Golden, Colorado 80401, USA

*corresponding author, ann.greenaway@nrel.gov

\section{Supporting Information}

\section{Composition and Phase Space}

For cation composition, Rutherford backscattering spectroscopy (RBS), a low-throughput method, was used to characterize $\mathrm{Mg} /(\mathrm{Mg}+\mathrm{Sn})$ for three points per sample library for four libraries to generate a calibration. Glassy carbon was used as a substrate to eliminate substrate overlap with the anion peaks (SI Figure 1A); additionally, a short growth time was used so that element signals (proportional to film thickness) would be well-resolved. X-ray fluorescence (XRF) mapping was used to quickly acquire composition spectra for full sample libraries. The XRF data was then converted to $\mathrm{Mg} /(\mathrm{Mg}+\mathrm{Sn})$ using RBS results and integrated peak areas from XRF. Figure S1B gives a comparison of RBS and calibrated XRF data for two sample libraries. The XRF calibration somewhat underestimates $\mathrm{Mg} /(\mathrm{Mg}+\mathrm{Sn})$ at the lowest $\mathrm{Mg}$ composition. 


\section{Energy $(\mathrm{MeV})$}

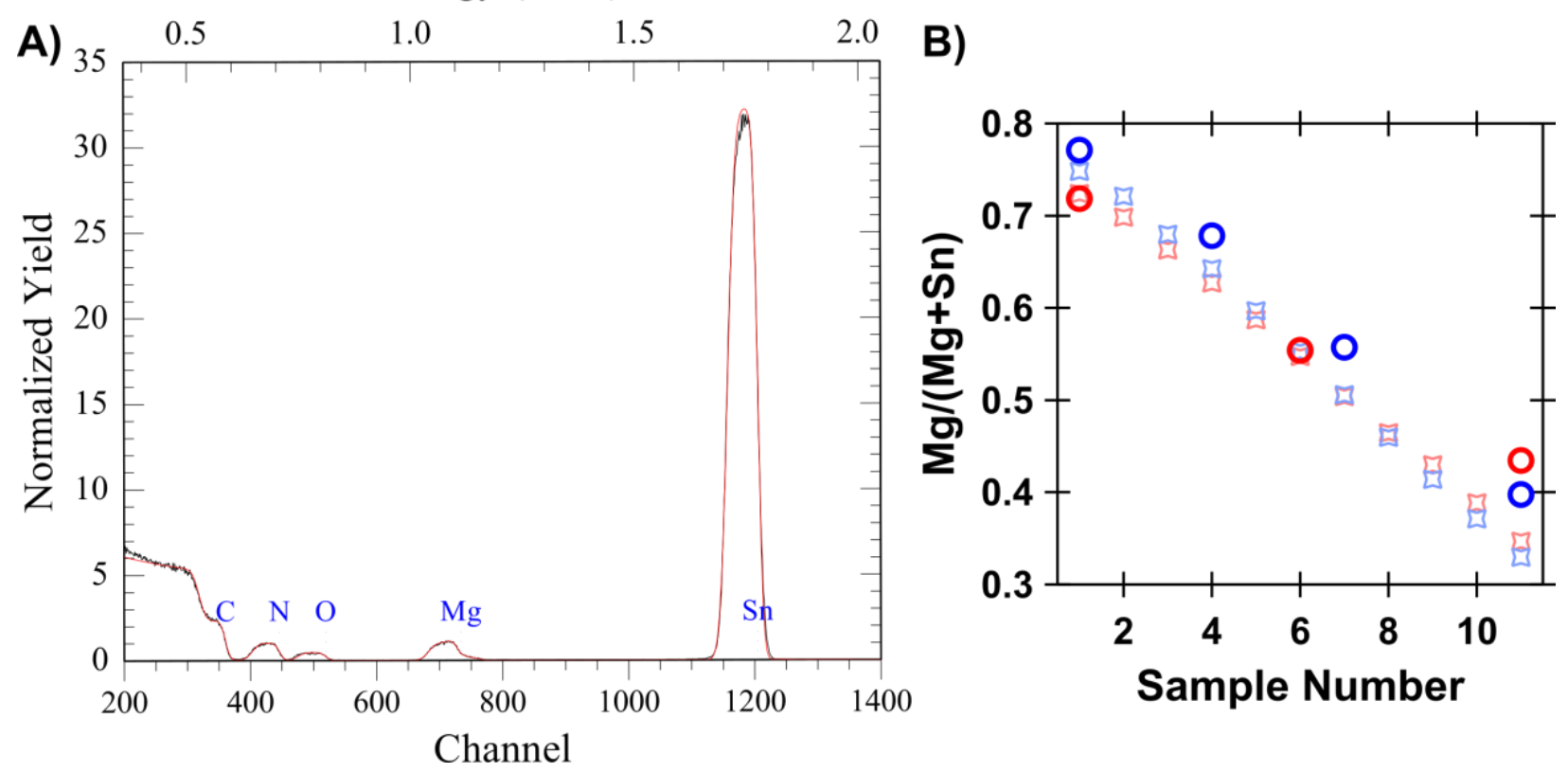

Figure S1: A) Example RBS data showing well-resolved signals for C, N, O, Mg, and Sn. Use of glassy carbon rather than Si eliminates overlap with the anion signals, simplifying analysis. B) Measured RBS (circles) and RBS-calibrated XRF (square shapes) data for two libraries, shown in separate colors.

The effect of changing stoichiometry on crystallinity can also be observed directly using $\mathrm{SEM}$ (Figure S2). At ambient temperature and below $\mathrm{Mg} /(\mathrm{Mg}+\mathrm{Sn})=0.5$, the films have very small grains with no preferred orientation, while above $\mathrm{Mg}=0.5$, triangular crystallites are formed that increase in size with increasing $\mathrm{Mg}$ content. Such crystallites are consistent with the columnar grains often observed in thin films grown by sputtering methods. The $\mathrm{Mg} \approx 0.5$ composition can also be compared across a range of temperatures: above $300^{\circ} \mathrm{C}$, grain size increases dramatically, with the largest grains observed at $400{ }^{\circ} \mathrm{C}$. The $500{ }^{\circ} \mathrm{C}$ sample returns to columnar morphology, possibly correlated to the (002) texturing observed in that library. 


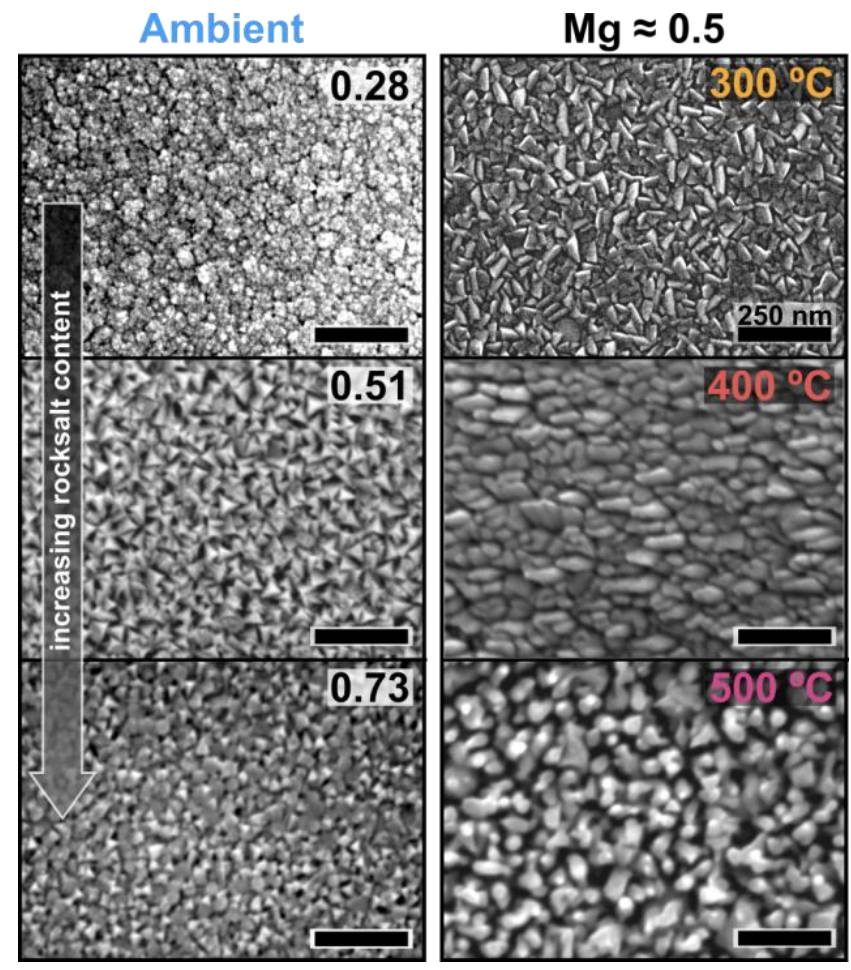

Figure S2: SEM comparisons of $\mathrm{MgSnN}_{2}$ samples with different $\mathrm{Mg} /(\mathrm{Mg}+\mathrm{Sn})$ deposited at ambient temperature (left column) and with $\mathrm{Mg} /(\mathrm{Mg}+\mathrm{Sn}) \approx 0.5$ deposited at different temperatures (right column).
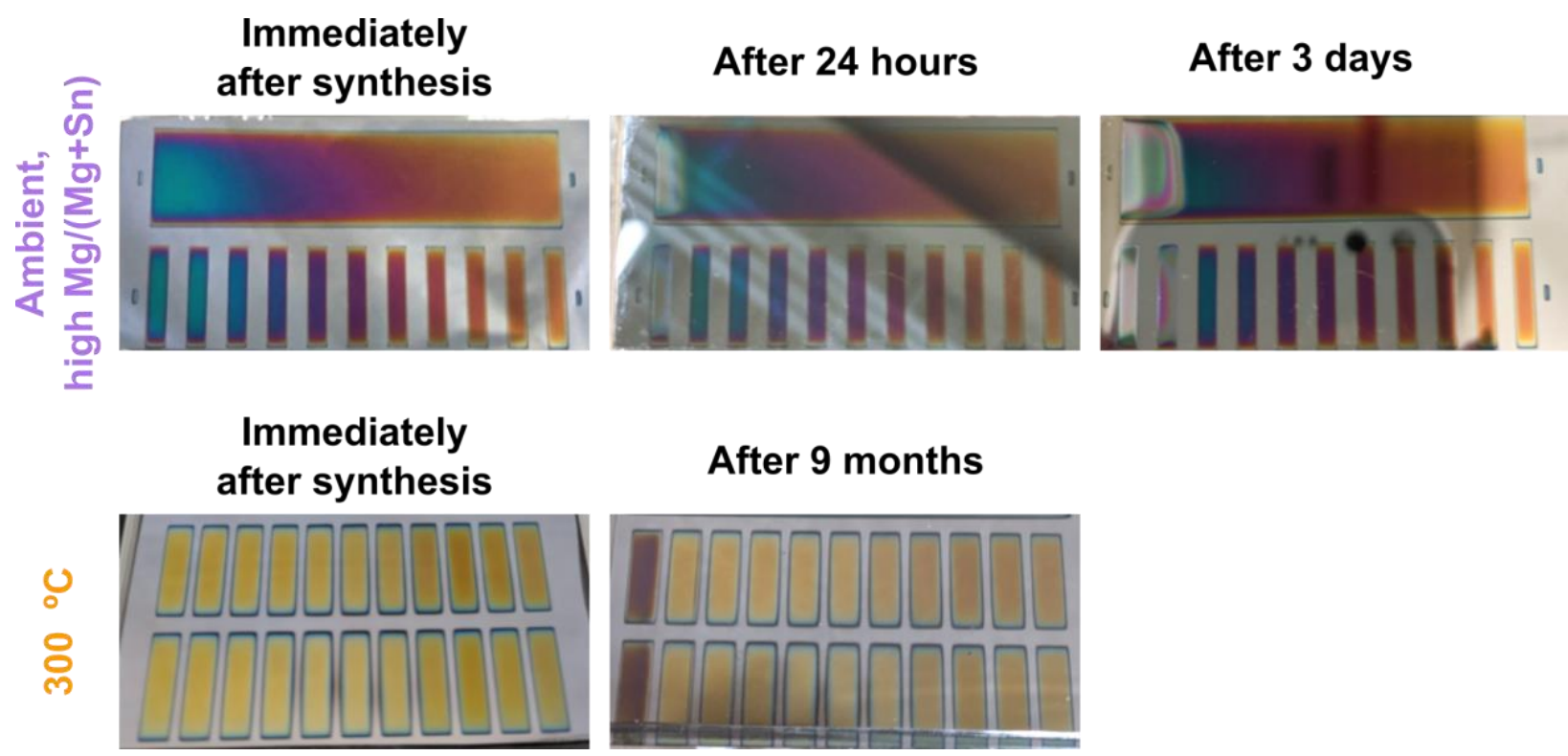

Figure S3: Photographs of sample libraries (with Mg-rich compositions on the left-hand side of each image) showing evolution of libraries with time. Top row: high $\mathrm{Mg} /(\mathrm{Mg}+\mathrm{Sn})$ content library, which rapidly oxidized even in a $\mathrm{N}_{2}$ environment. Bottom row: $300^{\circ} \mathrm{C}$ library showing a much smaller degree of oxidation after nine months. Library rows are 2 inches across. 


\section{Computational Investigation}

Table S1: Predicted structures with space group name and number; polymorph energies compared across multiple levels of computation; optoelectronic structure with band gaps, absorption thresholds $(\alpha=103 \mathrm{~cm}-1)$ with indirect/forbidden transitions marked with *, electron and hole effective masses, and electronic and ionic dielectric contributions.

\begin{tabular}{|c|c|c|c|c|c|c|c|c|c|c|c|}
\hline \multirow{2}{*}{$\begin{array}{l}\text { Polymorph } \\
\text { Type }\end{array}$} & \multicolumn{2}{|c|}{ Space Group } & \multicolumn{3}{|c|}{$\begin{array}{c}\text { Relative Energies } \\
\text { (meV/at) }\end{array}$} & \multicolumn{6}{|c|}{ Optoelectronic Structure } \\
\hline & Name & Number & PBE & SCAN & RPA & $\begin{array}{c}E_{\mathrm{g}} \\
(\mathrm{eV})\end{array}$ & $\begin{array}{c}E \text { at } \\
103\end{array}$ & $m *_{\mathrm{e} / \boldsymbol{m}}$ & $m * \mathrm{~h} / \boldsymbol{m}_{0}$ & $\varepsilon_{\mathrm{e}} / \varepsilon_{0}$ & $\varepsilon_{i} / \varepsilon_{0}$ \\
\hline \multirow{2}{*}{ Wurtzite } & $P n a 2_{1}$ & 33 & 0.0 & 0.0 & 0.0 & 2.47 & 2.60 & 0.22 & 2.4 & 4.8 & 4.3 \\
\hline & $P m c 21$ & 26 & 5.2 & 5.3 & 5.3 & 2.34 & 2.45 & 0.21 & 3.0 & 4.8 & 4.3 \\
\hline \multirow{2}{*}{ Zinc blende } & $I \overline{4} 2 d$ & 122 & 18.1 & 21.1 & 25.4 & 2.33 & 2.42 & 0.21 & 3.7 & 4.9 & 4.2 \\
\hline & $P \overline{4} m 2$ & 115 & 26.8 & 29.2 & 29.8 & 2.13 & 2.22 & 0.20 & 4.2 & 5.0 & 4.3 \\
\hline \multirow{2}{*}{ Rocksalt } & $P 2 / c$ & 13 & 90.3 & 67.5 & 70.0 & 3.17 & $3.56^{*}$ & 0.22 & 5.5 & 5.5 & 17.2 \\
\hline & I41/amd & 141 & 114.5 & 92.7 & 109.2 & 2.93 & $3.24 *$ & 0.23 & 7.7 & 6.0 & 21.5 \\
\hline
\end{tabular}

20 (Cu Ka, degrees)

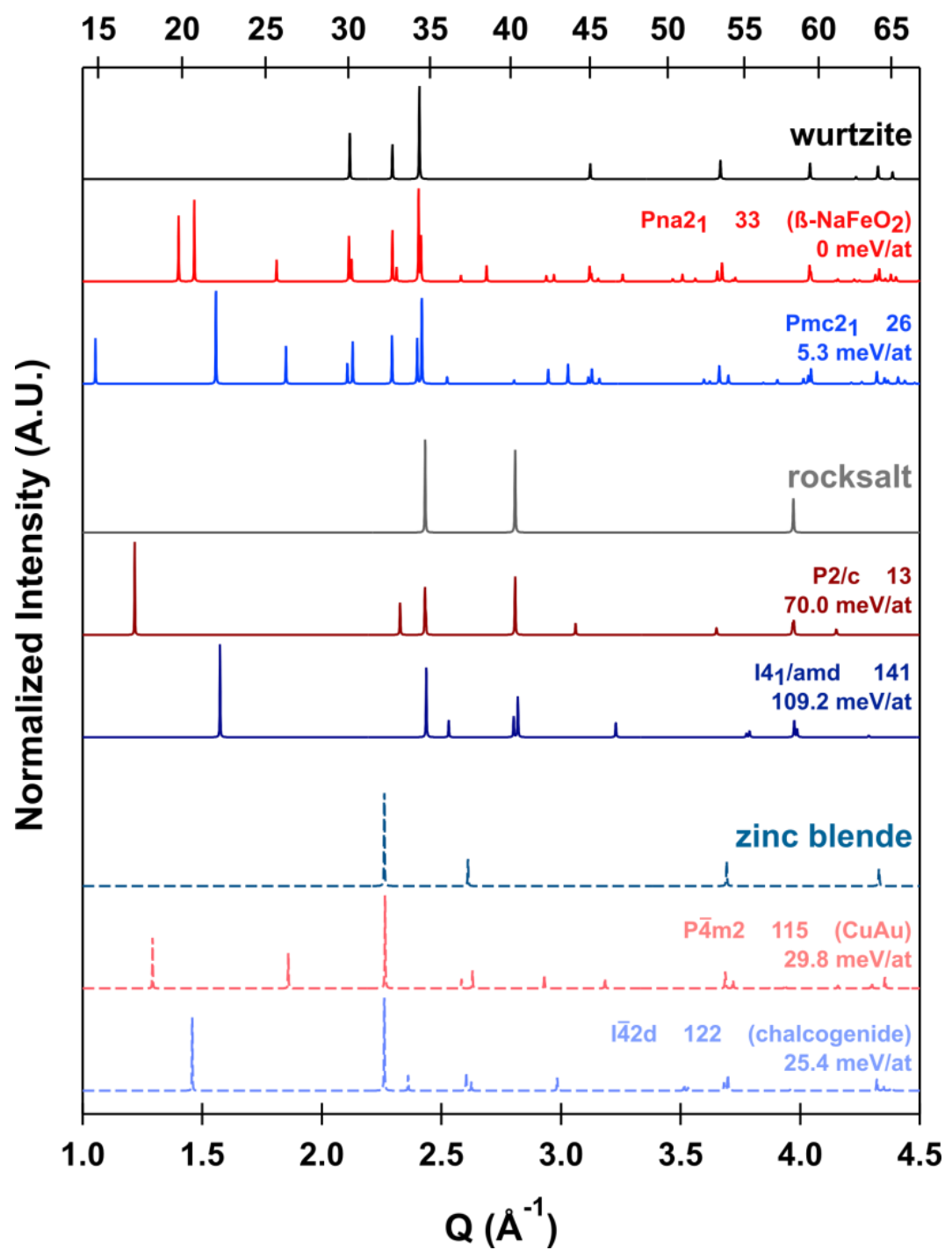

Figure S4: Calculated diffraction patterns for the three cation-disordered structure types for $\mathrm{MgSnN}_{2}$, each compared with the two lowest-energy ordered structures of that type. Both $Q$ and $2 \theta(\mathrm{Cu} \mathrm{K \alpha})$ are given. 


\section{Optoelectronic Properties}

Table S2: Hall effect measurement results for measurements performed at 40K.

\begin{tabular}{|c|c|c|c|c|c|}
\hline $\begin{array}{c}\text { Temperature } \\
\left({ }^{\circ} \mathbf{C}\right)\end{array}$ & $\begin{array}{c}\text { Approximate } \\
\mathbf{M g} /(\mathbf{M g}+\mathbf{S n})\end{array}$ & $\begin{array}{c}\text { Resistivity } \\
(\mathbf{\Omega} \bullet \mathbf{m})\end{array}$ & $\begin{array}{c}\text { Carrier } \\
\text { concentration } \\
(\mathbf{c m}-\mathbf{3})\end{array}$ & $\begin{array}{c}\text { Mobility } \\
(\mathbf{c m} 2 / \mathbf{V} \bullet \mathbf{s})\end{array}$ & $\begin{array}{c}\text { Hall voltage } \\
(\mathbf{V})\end{array}$ \\
\hline $\mathbf{3 0 0}$ & 0.5 & $4.65 \times 10_{-2}$ & $-7.5 \times 10_{19}$ & 1.79 & $-1.655 \times 10_{-3}$ \\
\hline $\mathbf{4 0 0}$ & 0.4 & $9.91 \times 10_{-2}$ & $-3.4 \times 10_{20}$ & 0.19 & $-6.297 \times 10-5$ \\
\hline
\end{tabular}

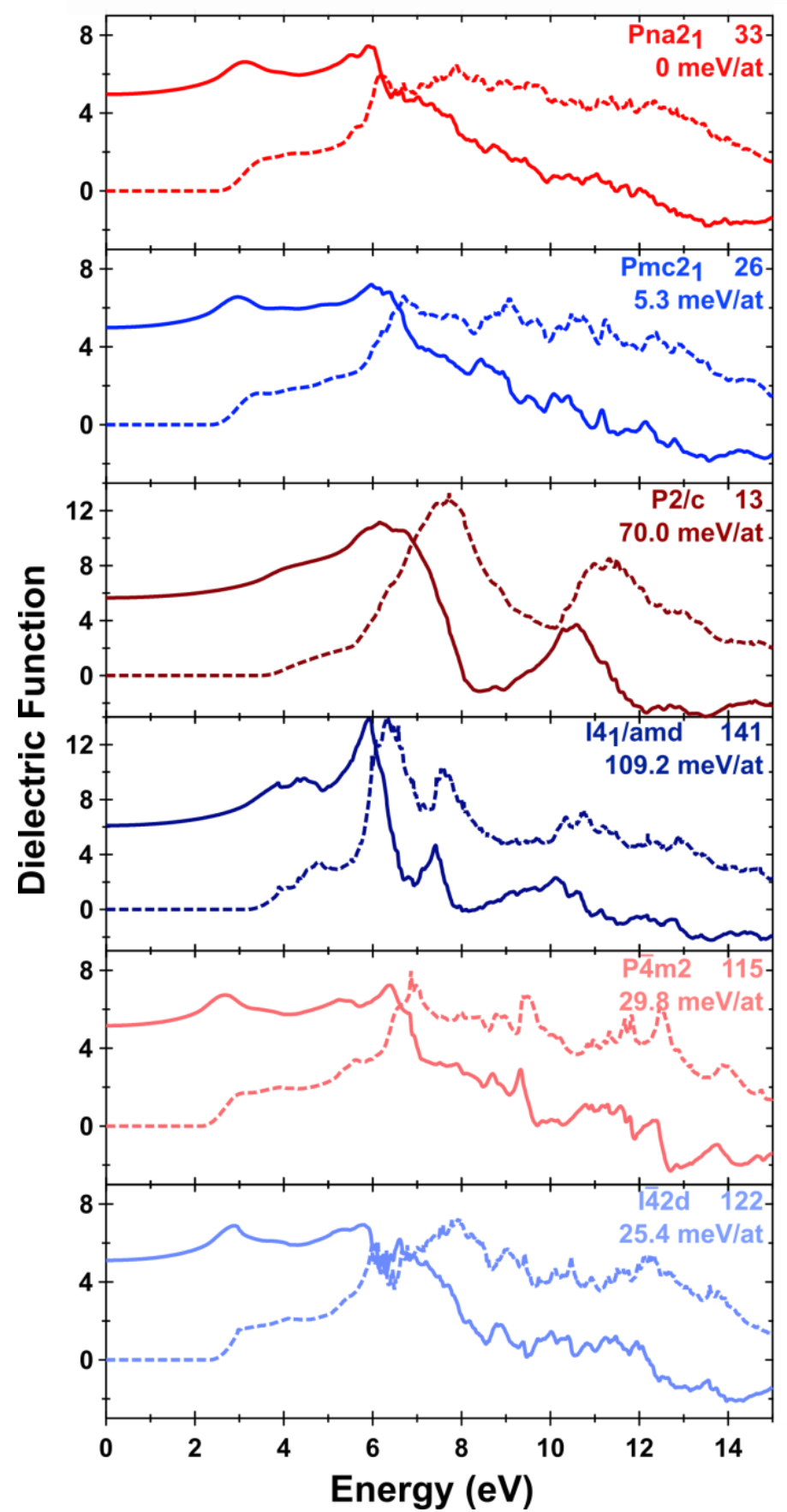

Figure S5: Calculated dielectric functions for the six lowest-energy ordered $\mathrm{MgSnN}_{2}$ structures discussed in Figure 2, with $\varepsilon 1$ (solid traces) and $\varepsilon_{2}$ (dashed traces) indicated separately. 

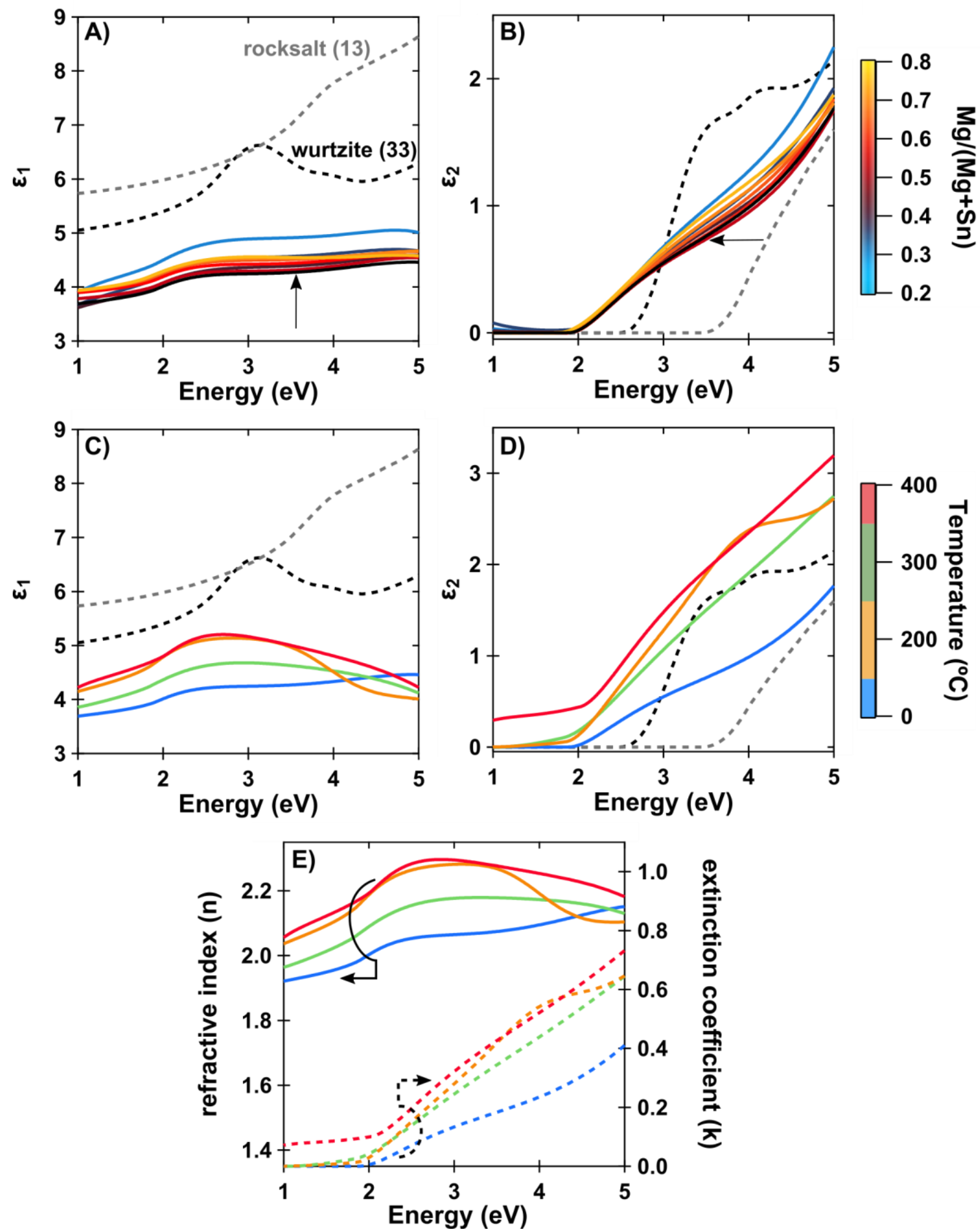

Figure S6: Additional optical properties calculated from spectroscopic ellipsometry. A) $\varepsilon_{1}$ and B) $\varepsilon 2$ for ambient temperature sample library presented in Figure 3A. The black arrows indicate the stoichiometric sample for this library. C) $\varepsilon 1$ and D) $\varepsilon 2$ for the $\mathrm{Mg} /(\mathrm{Mg}+\mathrm{Sn}) \approx 0.5$ samples presented in Figure 3B. Calculated $\varepsilon 1$ and $\varepsilon 2$ for the lowest-energy cation-ordered wurtzite (SG 33) and rocksalt (SG 13) are indicated with dashed lines in A-D. E) $n$ (solid traces) and $k$ (dashed traces) functions for the $\mathrm{Mg} /(\mathrm{Mg}+\mathrm{Ss}) \approx$ 0.5 samples, using the same color scale as C) and D). 


\section{Crystallographic Information Files}

Other supporting information includes CIFs for disordered wurtzite, rocksalt, and zinc blendederived forms of $\mathrm{MgSnN}_{2}$, as well as $\mathrm{MgSnN}_{2}$ in $\mathrm{SG}_{33}, 26,13,141,166,122$, and 115. 